\title{
Cytotoxicity of Dental Cements on Soft Tissue Associated with Dental Implants
}

\author{
Prashant Bajantri, ${ }^{1}$ Shobha J. Rodrigues $\mathbb{D}^{1},{ }^{1}$ K. Shama Prasada ${ }^{D},{ }^{2}$ Umesh Y. Pai, \\ Thilak Shetty, ${ }^{1}$ Sharon Saldanha, ${ }^{1}$ M. Mahesh, ${ }^{1}$ Puneeth Hegde, ${ }^{1}$ Ann Sales, \\ Sandipan Mukherjee, ${ }^{1}$ and Vignesh Kamath ${ }^{1}$ \\ ${ }^{1}$ Department of Prosthodontics, Manipal College of Dental Sciences, Mangalore, Manipal Academy of Higher Education, \\ Manipal, Karnataka, India \\ ${ }^{2}$ Department of Cell and Molecular Biology, Manipal School of Life Sciences, Manipal Academy of Higher Education, Manipal, \\ Karnataka, India
}

Correspondence should be addressed to Shobha J. Rodrigues; shobha.rodrigues@yahoo.com

Received 13 November 2021; Revised 9 December 2021; Accepted 27 December 2021; Published 20 January 2022

Academic Editor: Boonlert Kukiattrakoon

Copyright (c) 2022 Prashant Bajantri et al. This is an open access article distributed under the Creative Commons Attribution License, which permits unrestricted use, distribution, and reproduction in any medium, provided the original work is properly cited.

\begin{abstract}
Purpose. To investigate and compare the cellular host response of human gingival fibroblasts (HGF) on four currently used cements. Methods and Material. 5 cement pellet samples were made for each of the 4 test cements $(n=20)$. The cements used for this study were zinc phosphate, zinc oxide noneugenol (ZOE), RelyX U200, and glass ionomer cement (GIC). One commercially available cell line was used to investigate the cytotoxicity of peri-implant tissues. Direct contact cell culture testing was conducted following International Organization for Standardization (ISO) methods 10993-5 and 10993-12 (MTT assay test). Cell cultures without dental cement were considered as control. Cells were allowed to grow and confluence over 48 hours after subcultivation according to standard laboratory procedures. The cells were kept in direct contact with the cement samples for 24 hours before being subjected to analysis. All specimens were tested in triplicate to validate the results. Quantitative evaluation of cytotoxicity was done to measure cell death and inhibition of cell growth. Results were analyzed using 1-way ANOVA $(a=0.05)$ followed by Tukey B post hoc test. Results. The results of the study showed that HGF was vulnerable to the dental cement test material. GIC, zinc phosphate, ZOE, and resin cement were cytotoxic in decreasing order, respectively, and significantly reduced the cell viability after exposure to HGF $(p<0.001)$. Conclusions. Within the limitations of this in vitro cellular study, results indicated that the test dental cements were cytotoxic to HGF. The highest cytotoxicity was observed in GIC followed by zinc phosphate, ZOE, and resin cement.
\end{abstract}

\section{Introduction}

The replacement of missing teeth with endosseous implants for the rehabilitation of completely and partially edentulous patients has become the standard of care in dentistry. Prosthetic reconstruction with implants involves both cement-retained and screw-retained restorations.

Cement-retained restorations score over screw-retained on account of their ease of fabrication, better aesthetics, lower cost, and freedom of treatment planning $[1,2]$.

Another advantage of cement-retained prosthesis is that the restorative cement possesses shock-absorbing properties which decrease the force distribution into the alveolar bone via the implant assembly $[1,3,4]$. Lacking such shock-absorbing materials, the screw-retained prosthesis accumulates these stresses inside the implant assembly which may adversely affect their success rates [5].

One of the biggest challenges associated with cementretained prosthesis is the difficulty in clearing the residual cement used in the luting of the prosthesis to the dental implant which may leave behind excess cement in the soft tissues around the implant [6].

Studies indicate that this may occur in $8.6-14.4 \%$ of cases, with the largest incidences of residual cement being 
associated with subgingival margins of implant restorations [7-12].

The American Academy of Periodontology attributes excess cement around dental implants as a risk factor for peri-implant disease [13].

Peri-implant diseases are complex conditions associated with inflammatory processes that may affect the soft tissues (perimucositis) and/or hard tissues (peri-implantitis) associated with dental implants and are caused by an over-reactive immune response to a consortium of subgingival, largely anaerobic Gram-negative bacteria [14-21]. The effects of these peri-implant diseases may range from resorption of bone to complete failure of the implants $[22,23]$. In a study conducted by Raval et al., it was concluded that the human gingival fibroblasts (HGF) showed greater changes in cell viability than osteoblasts exposure to different luting cements [24].

The choice of luting cement for implant prosthesis also depends on the viscosity of the cement, ease of mixing, and the operator's preference. [25] In light of the above findings, it is imperative to study the nature of the luting cement and its effect on the peri-implant tissues to avoid failure of the implant.

This study aimed to investigate and compare the cellular host response of the HGF on exposure to four different commercially available test cements.

The null hypothesis was that there will be no difference in the cellular host response of the HGF in contact with the test cement.

\section{Methods and Material}

2.1. Preparation of the Test Cement. The four test cements used in the study are presented in Table 1. A total of 20 samples ( 5 cement pellets from each of the 4 types of cement) were molded in polytetrafluoroethylene (PTFE) polymer molds of dimensions $(7 \times 3 \times 3 \mathrm{~mm})$ following mixing of the respective cement in accordance with the manufacturer's instructions in an aseptic environment.

2.1.1. Preparation of Zinc Phosphate Cement. The powder was added in small increments to the liquid and mixed according to the manufacturer's instructions. Once the appropriate consistency was achieved, the cement was transferred to five polytetrafluoroethylene (PTFE) polymer molds. The setting time of cement was approximately 5-9 minutes.

2.1.2. Preparation of Glass Ionomer Cement (GIC) Samples. GIC powder and liquid were mixed according to the manufacturer's recommendation. Mixing was done by folding method to maintain the gel structure and was immediately transferred to the five PTFE molds. The GIC cement setting time was approximately 24 hours.

2.1.3. Preparation of Zinc Oxide Noneugenol Cement Samples. The base and catalysts were mixed on a mixing pad according to the manufacturer's recommendations and transferred to five PTFE molds. The setting time of zinc oxide noneugenol was approximately 3 minutes 30 seconds.
2.1.4. Preparation of Resin Cement Samples. The required quantity of material was dispensed from the clicker dispenser of the Automix syringe. Next, it was mixed and transferred to the five PTFE molds. The setting time of RelyX $^{\mathrm{TM}} \mathrm{U} 200$ cement was 30 seconds.

For all the experiments, the dimension of the mold used was $7 \times 3 \times 3 \mathrm{~mm}$. The cement once prepared was kept at room temperature for two days, washed with phosphate

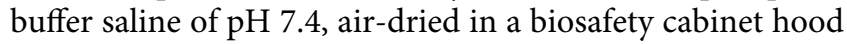
(NUAIR, USA), and used for all the experiments.

2.2. Evaluation of Cytotoxicity. The cytotoxicity of the four test cements was tested using in-house generated HGF by MTT assay test 3-(4,5-dimethylthiazol-2-yl)-2,5-diphenyltetrazolium bromide as published earlier [26, 27]. The HGF was cultured in DMEM containing 10\% FBS. All the cell lines were cultured and maintenance was carried out using class-II biosafety cell culture hood (Nuair, USA) and $\mathrm{CO}_{2}$ incubator (Thermo Fisher Scientific, USA). In brief, $1 \times 10$ [4] HGF were cultured in a 96-well plate and exposed to the four test cements by directly exposing them to the HGF for $24 \mathrm{hrs}$ at $37^{\circ} \mathrm{C}$ with $5 \% \mathrm{CO}_{2}$. At the end of $24 \mathrm{hrs}$, the cement was removed and incubated with MTT ( $5 \mathrm{mg} / \mathrm{ml}$, Sigma, USA) per well for $4 \mathrm{hrs}$ at $37^{\circ} \mathrm{C}$ with $5 \% \mathrm{CO}_{2}$. Subsequently, the supernatant was removed, and the formazan crystals were dissolved with $150 \mu \mathrm{L}$ of DMSO (Sigma, USA). The absorbance was measured at $570 \mathrm{~nm}$ and $630 \mathrm{~nm}$ using a microplate reader (Varioskan, Thermo Fisher Scientific, USA). All the experiments are conducted in triplicates and repeated 3 times.

\section{Results}

In the present study, we tested the cytotoxic effect of 4 dental cements, namely, zinc phosphate, zinc oxide noneugenol, resin cement, and glass ionomer using MTT assay. The setting time for zinc phosphate cement, glass ionomer cement, zinc oxide noneugenol cement, and resin cement was 5 to 9 minutes, 24 hours, 3 minutes 30 seconds, and 30 seconds, respectively. The cement blocks were kept at room temperature, washed with PBS, air-dried under aseptic conditions, and directly exposed to HGF for $24 \mathrm{hrs}$. The cell viability was evaluated $24 \mathrm{hrs}$ after exposure using MTT assay. The unexposed cells were kept as a control group. Table 2 summarizes the quantitative analysis of the cytotoxicity testing after direct exposure of four test cements to HGF. Table 3 shows the intergroup comparison of HGF mean cell count after 24-hour direct contact exposure to various dental cement materials using the post hoc Tukey test $(P<0.05)$. The HGF viability in control, zinc phosphate cement, glass ionomer cement, zinc oxide noneugenol cement, and resin cement was $99.35 \%, 2.46 \%, 2.21 \%, 6.6 \%$, and $12.97 \%$, respectively (Figure 1(a)). Resin cement showed the highest cell viability when compared with the other three cements tested (Figure 1(b)). Zinc oxide noneugenol cement also showed significantly better cell viability when compared with zinc phosphate cement and glass ionomer cement. Among the four cements tested, zinc phosphate cement and glass ionomer cement showed least cell viability. 
TABLE 1: Dental cement investigated.

\begin{tabular}{lccc}
\hline Cement type (groups) & Product name & Manufacturer & Setting time \\
\hline Zinc phosphate & De Trey Zinc & Dentsply Sirona & $5-9$ minutes \\
Zinc oxide noneugenol & RelyX ${ }^{\mathrm{TM}}$ Temp NE & $3 \mathrm{M}$ ESPE & 3 minutes 30 seconds \\
Resin cement & RelyX ${ }^{\mathrm{TM}}$ U200 & $3 \mathrm{M} \mathrm{ESPE}$ & 24 hours \\
Glass ionomer & GC Gold Label & GC I & 30 seconds \\
\hline
\end{tabular}

TABle 2: Comparison of the viability of all the 4 experimental groups and the control group.

\begin{tabular}{lcccc}
\hline Groups & $N$ & Mean & Std. deviation & Mean square/F statistic \\
\hline Control & 4 & 99.353846 & 2.4079349 & $7345.647 / 3210.079$ \\
ZOE & 5 & 6.642051 & 0.4139323 & \\
Zinc phosphate & 5 & 2.461538 & 0.4501150 & \\
Resin cement & 5 & 12.976410 & 2.4410946 & \\
GIC & 5 & 2.219487 & 0.4335442 & \\
Total & 24 & & & \\
\hline
\end{tabular}

TABLE 3: Intergroup comparison of HGF mean cell count after 24-hour direct contact exposure to various dental cement materials using post hoc Tukey test.

\begin{tabular}{|c|c|c|c|c|}
\hline Group & Comparison with & Mean difference & Standard error & $P$ value \\
\hline \multirow{4}{*}{ Control } & $\mathrm{ZOE}$ & $92.7117949^{*}$ & 1.2181156 & $\leq 0.001$ \\
\hline & Zinc phosphate & $96.8923077^{*}$ & 1.2206794 & $<0.001$ \\
\hline & Resin cement & $86.3774359^{* *}$ & 1.6252157 & $<0.001$ \\
\hline & GIC & $97.1343590^{*}$ & 1.2194793 & $\overline{<0.001}$ \\
\hline \multirow{3}{*}{$\mathrm{ZOE}$} & Zinc phosphate & 4.1805128 & 0.2734752 & $\leq 0.001$ \\
\hline & Resin cement & $-6.3343590^{*}$ & 1.1072744 & $\underline{0.038}$ \\
\hline & GIC & $4.4225641^{*}$ & 0.2680673 & $\overline{\leq 0.001}$ \\
\hline \multirow{2}{*}{ Zinc phosphate } & Resin cement & $-10.5148718^{*}$ & 1.1100943 & 0.005 \\
\hline & GIC & 0.2420513 & 0.2794867 & $\overline{0.995}$ \\
\hline Resin cement & GIC & $10.7569^{*}$ & 1.1087 & 0.005 \\
\hline
\end{tabular}

HGF, fibroblast cell line; ${ }^{*} P<0.05$.

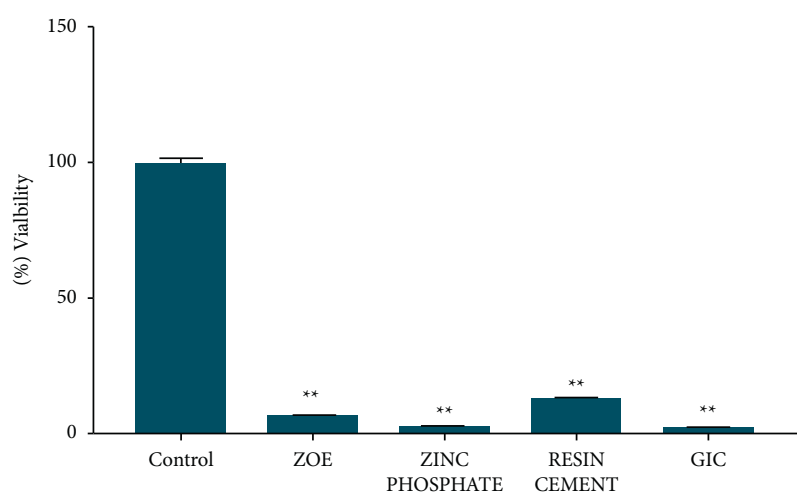

(a)

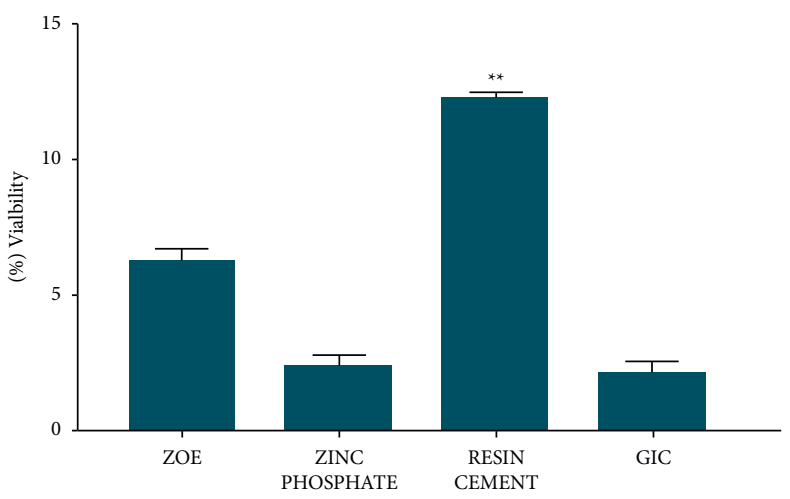

(b)

Figure 1: The effect of direct cement exposure on the viability of HGF cells. The cement was prepared and allowed to be set as per the manufacturer's protocol. The HGF cell viability was tested by MTT assay following 24 hours of exposure. (a) The bar graph represents the HGF viability after 24 hours of exposure along with control cells. (b) The bar graph represents the comparison of HGF viability upon exposure to four dental cements. All the experiments are performed in triplicate and repeated 3 times. ${ }^{*} P<0.05$ was considered statistically significant.

\section{Discussion}

This study investigated and compared the cellular host response of $\mathrm{HGF}$ to 4 different dental types of cement. All the HGF demonstrated cytotoxic effects when exposed to the test cement. Therefore, the null hypothesis that there would be no difference in the cellular response of fibroblasts on exposure to various test cements was rejected.
The control group demonstrated significantly higher viability of gingival fibroblasts as compared to test groups. This corroborates with the study conducted by Rodriguez et al. [28], where it was found that human gingival fibroblasts were sensitive to acrylic resin, zinc oxide eugenol, and zinc phosphate cement and this exposure significantly reduced their cellular viability. In comparison of the control group with the zinc oxide eugenol group, zinc phosphate group and resin cement group, 
and GIC group, the viability of cells in the control group was found to be significantly higher. This suggests that the gingival fibroblasts are sensitive to cement exposure. According to Rodriguez et al. [28], both the soft tissues (fibroblasts) and the hard tissues (osteoblasts) are sensitive to commercially available luting cement. Their study also suggested that osteoblasts are comparatively less affected by the cement than fibroblasts. The findings of this study are in agreement with a study conducted by Schwap et al. and Trumpate et al. in which resin-based materials showed toxicity in cell culture tests $[29,30]$. A study conducted by Stanislawski et al. [31] showed that the presence of fluoride, strontium, and aluminium ions in glass ionomer cement was lesser than the concentration needed to cause cytotoxicity to the tissues and concluded that the other major constituents of GIC are the main causative factors which contribute to its cytotoxic effect. A study conducted by Inoue et al. showed that the more the unreacted material, the higher was the toxicity of the material [32]. Sun et al. [33] tested the cytotoxicity of 3 different self-adhesive types of cement (RelyX U200, Maxcem Elite, and Multilink Speed) with and without light irradiation. The results of this study showed that cell apoptosis or necrosis rate of RelyX U200 and Maxcem Elite with light irradiation was higher than those without light irradiation. The cytotoxicity demonstrated by resin cement may be triggered by the release of monomers. Greater the content of the unreacted material, lesser would be the degree of conversion and therefore higher the cytotoxic effect [34-37].

Previous studies have shown that this reduction in cytotoxicity increases with time until no toxicity is detectable after 6 weeks $[31,38]$; in a study conducted by Wilson et al. [7], it was found that in $81 \%$ of the implants that showed sulcular bleeding and/or suppuration, residual cement was present. The residual cement was then removed, and four weeks after removal of the cement in $75.7 \%$ of the cases, no signs of inflammation were noticeable. The present study however studied the effect of cytotoxicity over a 24-hour period which may be considered a limitation of this study.

\section{Conclusion}

Within the limitations of this in vitro study, the following conclusions were drawn: all the luting cements are cytotoxic to the gingival fibroblast cells; mmaximum cytotoxicity was demonstrated in GIC followed by zinc phosphate, zinc oxide noneugenol, and resin cement.

\section{Data Availability}

Data are available on request; kindly contact the corresponding author.

\section{Conflicts of Interest}

The authors declare that they have no conflicts of interest.

\section{References}

[1] K. S. Hebel and R. C. Gajjar, "Cement-retained versus screwretained implant restorations: achieving optimal occlusion and esthetics in implant dentistry," The Journal of Prosthetic Dentistry, vol. 77, no. 1, pp. 28-35, 1997.

[2] W. Chee and S. Jivraj, "Screw versus cemented implant supported restorations," British Dental Journal, vol. 201, no. 8, pp. 501-507, 2006.

[3] D. L. Guichet, "Load transfer in screw-and cement-retained implant fixed partial denture designs," The Journal of Prosthetic Dentistry, vol. 72, p. 361, 1994.

[4] R. Pietrabissa, L. Gionso, V. Quaglini, E. Di Martino, and M. Simion, "An in vitro study on compensation of mismatch of screw versus cement-retained implant supported fixed prostheses," Clinical Oral Implants Research, vol. 11, no. 5, pp. 448-457, 2000.

[5] T. D. Taylor and J. R. Agar, "Twenty years of progress in implant prosthodontics," The Journal of Prosthetic Dentistry, vol. 88, no. 1, pp. 89-95, 2002.

[6] W. Chee, D. A. Felton, P. F. Johnson, and D. Y. Sullivan, "Cemented versus screw-retained implant prostheses: which is better?" The International Journal of Oral \& Maxillofacial Implants, vol. 14, pp. 137-141, 1999.

[7] T. G. Wilson Jr, "The positive relationship between excess cement and peri-implant disease: a prospective clinical endoscopic study," Journal of Periodontology, vol. 80, no. 9, pp. 1388-1392, 2009.

[8] T. Linkevicius, A. Puisys, E. Vindasiute, L. Linkeviciene, and P. Apse, "Does residual cement around implant-supported restorations cause peri-implant disease? A retrospective case analysis," Clinical Oral Implants Research, vol. 24, pp. 11791184, 2012.

[9] J. R. Agar, S. M. Cameron, J. C. Hughbanks, and M. H. Parker, "Cement removal from restorations luted to titanium abutments with simulated subgingival margins," The Journal of Prosthetic Dentistry, vol. 78, no. 1, pp. 43-47, 1997.

[10] T. Berglundh, L. Persson, and B. Klinge, "A systematic review of the incidence of biological and technical complications in implant dentistry reported in prospective longitudinal studies of at least 5 years," Journal of Clinical Periodontology, vol. 29, pp. 197-212, 2002.

[11] B. E. Pjetursson, K. Tan, N. P. Lang, U. Bragger, M. Egger, and M. Zwahlen, "A systematic review of the survival and complication rates of fixed partial dentures (FPDs) after an observation period of at least 5 years. IV. Cantilever or extension FPDs," Clinical Oral Implants Research, vol. 15, no. 6, pp. 667-676, 2004.

[12] T. Linkevicius, E. Vindasiute, A. Puisys, and V. Peciuliene, "The influence of margin location on the amount of undetected cement excess after delivery of cement-retained implant restorations," Clinical Oral Implants Research, vol. 22, no. 12, pp. 1379-1384, 2011.

[13] P. Rosen, D. Clem, D. Cochran et al., "Peri-implant mucositis and peri-implantitis: a current understanding of their diagnoses and clinical implications," Journal of Periodontology, vol. 84, pp. 436-443, 2013.

[14] N. P. Lang, T. Berglundh, and Working Group 4 of Seventh European Workshop on Periodontology, "Periimplant diseases: where are we now? Consensus of the seventh European workshop on periodontology," Journal of Clinical Periodontology, vol. 38, pp. 178-181, 2011.

[15] R. M. Meffert, "Periodontitis vs. peri-implantitis: the same disease? The same treatment?" Critical Reviews in Oral Biology \& Medicine, vol. 7, no. 3, pp. 278-291, 1996.

[16] A. Mombelli and F. Décaillet, "The characteristics of biofilms in peri-implant disease," Journal of Clinical Periodontology, vol. 38, pp. 203-213, 2011. 
[17] B. E. Pjetursson, C. Helbling, H.-P. Weber et al., "Periimplantitis susceptibility as it relates to periodontal therapy and supportive care," Clinical Oral Implants Research, vol. 23, no. 7, pp. 888-894, 2012.

[18] M. O. Freire, P. P. Sedghizadeh, C. Schaudinn et al., "Development of an animal model for Aggregatibacter actinomycetemcomitans biofilm-mediated oral osteolytic infection: a preliminary study," Journal of Periodontology, vol. 82, no. 5, pp. 778-789, 2011.

[19] A. Lee and H.-L. Wang, "Biofilm related to dental implants," Implant Dentistry, vol. 19, no. 5, pp. 387-393, 2010.

[20] G. Liddelow and I. Klineberg, "Patient-related risk factors for implant therapy. A critique of pertinent literature," Australian Dental Journal, vol. 56, no. 4, pp. 417-426, 2011.

[21] J. D. Bumgardner, P. Adatrow, W. O. Haggard, and P. A. Norowski, "Emerging antibacterial biomaterial strategies for the prevention of peri-implant inflammatory diseases," The International Journal of Oral \& Maxillofacial Implants, vol. 26, pp. 553-560, 2011.

[22] N. Pauletto, B. J. Lahiffe, and J. N. Walton, "Complications associated with excess cement around crowns on osseointegrated implants: a clinical report," The International Journal of Oral \& Maxillofacial Implants, vol. 14, pp. 865-868, 1999.

[23] R. Gapski, N. Neugeboren, A. Z. Pomeranz, and M. W. Reissner, "Endosseous implant failure influenced by crown cementation: a clinical case report," The International Journal of Oral \& Maxillofacial Implants, vol. 23, pp. 943-946, 2008.

[24] N. C. Raval, C. P. K. Wadhwani, S. Jain, and R. P. Darveau, "The interaction of implant luting cements and oral bacteria linked to peri-implant disease: an in vitro analysis of planktonic and biofilm growth - a preliminary study," Clinical Implant Dentistry and Related Research, vol. 17, no. 6, pp. 1029-1035, 2015.

[25] D. Y. Tarica, V. M. Alvarado, and S. T. Truong, "Survey of United States dental schools on cementation protocols for implant crown restorations," The Journal of Prosthetic Dentistry, vol. 103, no. 2, pp. 68-79, 2010.

[26] International Organization for Standardization, Biological Evaluation of Medical Devices -Part 5: Tests for in Vitro Cytotoxicity, International Organization for Standardization, Geneva, Switzerland, 2009.

[27] International Organization for Standardization, Biological Evaluation of Medical Devices-Part 12: Sample Preparation and Reference Materials, Vol. 12, International Organization for Standardization, , Geneva, Switzerland, 2012.

[28] L. C. Rodriguez, J. N. Saba, K.-H. Chung, C. Wadhwani, and D. C. Rodrigues, "In vitro effects of dental cements on hard and soft tissues associated with dental implants," The Journal of Prosthetic Dentistry, vol. 118, no. 1, pp. 31-35, 2017.

[29] M. Schmid-Schwap, A. Franz, F. König et al., "Cytotoxicity of four categories of dental cements," Dental Materials, vol. 25, no. 3, pp. 360-368, 2009.

[30] R. Trumpaite-Vanagiene, V. Bukelskiene, J. Aleksejuniene, A. Puriene, D. Baltriukiene, and V. Rutkunas, "Cytotoxicity of commonly used luting cements-an in vitro study," Dental Materials Journal, vol. 34, no. 3, pp. 294-301, 2015.

[31] A. Schedle, A. Franz, X. Rausch-Fan et al., "Cytotoxic effects of dental composites, adhesive substances, compomers and cements,” Dental Materials, vol. 14, no. 6, pp. 429-440, 1998.

[32] K. Inoue, H. Arikawa, K. Fujii et al., "Composite restorative resins: Part 3: cytotoxicity test to mouse fibroblasts in culture of UV and visible light-activated composite resins," Dental Materials Journal, vol. 7, no. 1, pp. 55-61, 1988.
[33] F. Sun, Y. Liu, Y. Pan, M. Chen, and X. Meng, "Cytotoxicity of self-adhesive resin cements on human periodontal ligament fibroblasts," BioMed Research International, vol. 2018, Article ID 7823467, 10 pages, 2018.

[34] C. T. Hanks, M. Anderson, and R. G. Craig, "Cytotoxic effects of dental cements on two cell culture systems," Journal of Oral Pathology \& Medicine, vol. 10, no. 2, pp. 101-112, 1981.

[35] D. Welker and G. Neupert, "Vergleichende in vitro Studie zellulärer Reaktionen auf lösliche bestandteile von EBA- und Phosphat-Zement," Deutsche Zahnärztliche Zeitschrift, vol. 30, pp. 522-526, 1975.

[36] J. Leiskar and K. Helgeland, "Toxicity of some dental cements in a cell culture system," Scandinavian Journal of Dental Research, vol. 85, pp. 471-479, 1977.

[37] M. J. Tyas, "In vitro toxicity tests of zinc phosphate cement," Journal of Oral Rehabilitation, vol. 5, no. 4, pp. 339-347, 1978.

[38] A. Franz, F. König, M. Anglmayer et al., "Cytotoxic effects of packable and nonpackable dental composites," Dental Materials, vol. 19, no. 5, pp. 382-392, 2003. 